\title{
Late Miocene Red River submarine fan, northwestern South China Sea
}

\author{
WANG YingMin ${ }^{1,2 *}$, XU Qiang ${ }^{3}$, LI Dong ${ }^{1}$, HAN JianHui ${ }^{4}$, LÜ Ming ${ }^{3}$, WANG YongFeng ${ }^{1}$, \\ LI WeiGuo ${ }^{5}$ \& WANG HaiRong 6 \\ ${ }^{1}$ College of Geosciences, China University of Petroleum, Beijing 102249, China; \\ ${ }^{2}$ State Key Laboratory of Petroleum Resources and Prospecting, China University of Petroleum, Beijing 102249, China; \\ ${ }^{3}$ The Research Institute of CNOOC, Beijing 100027, China; \\ ${ }^{4}$ School of Energy Resources, Chengdu University of Technology, Chengdu 610059, China; \\ ${ }^{5}$ BP America Inc, Houston, TX 77079, USA; \\ ${ }^{6}$ School of Energy Resources, China University of Geosciences, Beijing 100083, China
}

Received June 17, 2010; accepted December 31, 2010

\begin{abstract}
A huge submarine fan is discovered through the research of the seismic and borehole data in the binding site of Yinggehai basin and Qiongdongnan basin in northwestern South China Sea. The fan, mainly formed during Late Miocene (Huangliu period) has an area over $10000 \mathrm{~km}^{2}$ and maximum thickness of over $2000 \mathrm{~m}$. It is characterized by a wedge-shaped oblique progradation configuration on the dip profile and a hummocky bidirectional progradation configuration on the strike profile. The core and Logging data from the well YC35-1-2 located in the front side of the fan indicate that sandy gravity flow deposits are predominant in lower Huangliu Formation and change to interbeds of sand and mud in upper Huangliu Formation. The fan is interpreted as a sand/mud-rich submarine fan in combination with the bathyal geological background of Huangliu period. A preliminary analysis of provenance indicates that neither the Guiren Uplift in the west nor the Hainan Uplift in the north can serve as the major provenance for the submarine fan. The provenance is considered to be from the Red River, based on the sedimentary facies study of the Huangliu Formation in Yinggehai basin. The fan is thus named as "Red River submarine fan". The Red River depositional system consists of the Red River submarine fan, the Red River delta, and associated submarine canyons. The discovery of the Red River submarine fan provides important information for the research of the uplift of Tibetan Plateau and the evolvement of Red River Fault Zone. Furthermore, it also points out a new direction for the deepwater hydrocarbon exploration in the northern South China Sea.
\end{abstract}

Red River submarine fan, Red River depositional system, uplift of the Tibetan Plateau, deepwater hydrocarbon exploration, northern South China Sea

Citation: $\quad$ Wang Y M, Xu Q, Li D, et al. Late Miocene Red River submarine fan, northwestern South China Sea. Chinese Sci Bull, 2011, 56: 1488-1494, doi: $10.1007 / \mathrm{s} 11434-011-4441-\mathrm{z}$

Deepwater is one of the main focuses in global hydrocarbon exploration activities. Large submarine fans are the main targets of deepwater exploration, and are also the frontier in sedimentological studies in recent years. Many submarine fans develop in front of large deltas feed by subcontinentalor even continental-scale rivers. For example, major river

*Corresponding author (email: wym3939@vip.sina.com) systems such as the Mississippi, the Niger, and the Ganges all have their associated submarine fans, in which deepwater hydrocarbon exploration is in great success. In the middle segment of the northern slope of the South China Sea, where deepwater exploration are very active in recent years, a large submarine fan in front of the paleo Pearl River Delta, the Baiyun fan, is discovered. The deepwater fan has been proved prolific by several wells drilled on key 
structures, including the LW3-1 well, the LH34-1 well, and the LH29-1 well. The Red River is another major river system that has transported sediments to the west segment of the northern slope of the South China Sea. The questions are: Is there a submarine fan developed in front of the paleo Red River Delta? If yes, when does it form? How well its associated sands are developed and where are they distributed? The answers to these questions not only have great significance from hydrocarbon exploration in this segment of the northern slope, but also will contribute to understand the uplift of the Tibetan Plateau and the evolution of Red River Fault Zone.

Theoretically, in front of large river deltas such as the Red River Delta, there should be submarine fans. Previous studies investigating their potential occurrence, however, are very limited, and in the published literatures there is only one paper with a schematic illustrating the development of a submarine fan in the Yinggehai Basin [1]. However, it does not provide direct evidence for when and how the fan was formed.

Based on the detailed analysis of a large amount of regional seismic profiles, a large submarine fan was discovered in the Huangliu Formation at the junction between the Yinggehai Basin and the Qiongdongnan Basin, east of the Guiren Uplift. It is named as the Red River submarine fan considering that it is located in front of the Red River Delta and is mainly feed by the paleo Red River. The Red River depositional system is composed of the Red River submarine fan, the Red River Delta, and associated submarine canyons.

\section{Evidence for the occurrence of the submarine fan}

\subsection{Seismic facies characteristics}

On seismic profiles to the east of the Guiren Uplift, across the junction between the Yinggehai and the Qiongdongnan basins, there is a giant sedimentary unit between reflections S30 and S40 (the Huangliu Formation). From the west to the east of the uplift, along depositional dip, the unit shows wedge-shaped, oblique, progradational reflection configuration and thins out (Figure 1(a)). Along strike, it is characterized by bidirectional downlapping geometry (Figure 1(b)). These are all typical seismic expression of sand-/mudrich submarine fans [2]. Vertically, two different seismic facies are identified: the lower (the Huang2 Member) and the upper (the Huang1 Member). The lower seismic facies show low amplitude and poor continuity, with abundant small-scale erosional scours; whereas the upper facies have higher amplitude and better continuity, with less scours. This is interpreted as the result of simpler lithology in Huang2 Member than in the overlying Huang1 Member. In fact, core and log data show that the lower member is dominated by thick massive sandstones and conglomeritic sandstones, and the upper member is more heterolithic with many muddy intervals. Successions in the formation show an overall fining-upward trend, very typical to many gravity flow deposits. During the Huangliu Stage, the Yingqiong Basin is in bathyal environment. The fan, thus, is interpreted as a submarine fan.

The progradational reflection configuration is over 100 $\mathrm{km}$ along both dip and strike, indicating that the area of the fan is over $10000 \mathrm{~km}^{2}$. The thickest part of the fan, over $2000 \mathrm{~m}$, is immediately adjacent to the Guiren Uplift.

\subsection{Drilling geology}

The YC35-1-2 well penetrates the front side of the submarine fan (see Figure 1 for location). Log data from the well show that deposits in the Huangliu Formation overall fine upward and there are 8 smaller fining-upward cycles in it (Figure 2). Nearly $180 \mathrm{~m}$ cores (4654.3-4835.4 m) are collected continuously from the lower 3 cycles, which provide valuable information for the identification of facies.

The lowest cycle can be subdivided into two parts (Figure 3$)$. The lower part $(4773-4828 \mathrm{~m})$ is characterized by low gamma, low density, middle-high resistivity, and low sonic. Gamma and resistivity curves are box-shaped with ratty signature. It is dominated by pebbly coarse feldspathic quartz arenite (quartz 59\%, feldspar 10.9\%, and lithics $7.1 \%$ ). The bottom of the cycle consists of relatively high carbonate clasts and deposits are characterized by mixed proximal carbonate and distal clastic. Five episodes of proximal lobe deposition, 8 episodes of channel deposition, and two episodes of overbank deposition are identified in the outer fan. The proximal lobe successions mainly consist of sandy debris and grain flow deposits and are dominated by pebbly fine sandstones with quartz gravels and occasional occurrence of mud clasts. The sandstones are typically inversely-graded and/or massive with medium-sorted and well-rounded framework grains. These successions show low gamma, high resistivity, low sonic and density, and a funnel-shaped signature on gamma and resistivity logs. The channel successions consist of fine- to mediumgrained pebbly sandstones deposited under grain flows and overall fine upward. These successions are characterized by low gamma, high resistivity, and low sonic and density, and bell-shaped or ratty bell-shaped signatures on gamma and resistivity logs. The overbank deposits are dominated by fine, well-sorted, well-rounded, massive turbidites, and typically show high gamma, low resistivity and density, and high sonic. Gamma and resistivity curves are away from the shale line and are slightly ratty.

Deposits in the upper part of the cycle (4753-4773 m) are characterized by high density, low resistivity, and high sonic. Gamma and resistivity logs are straight and close to the shale line. It is dominated by dark mudstones with very fine-grained thin bedded sandstones, interpreted as hemipelagic interbedded with lower-fan distal lobe deposits. 


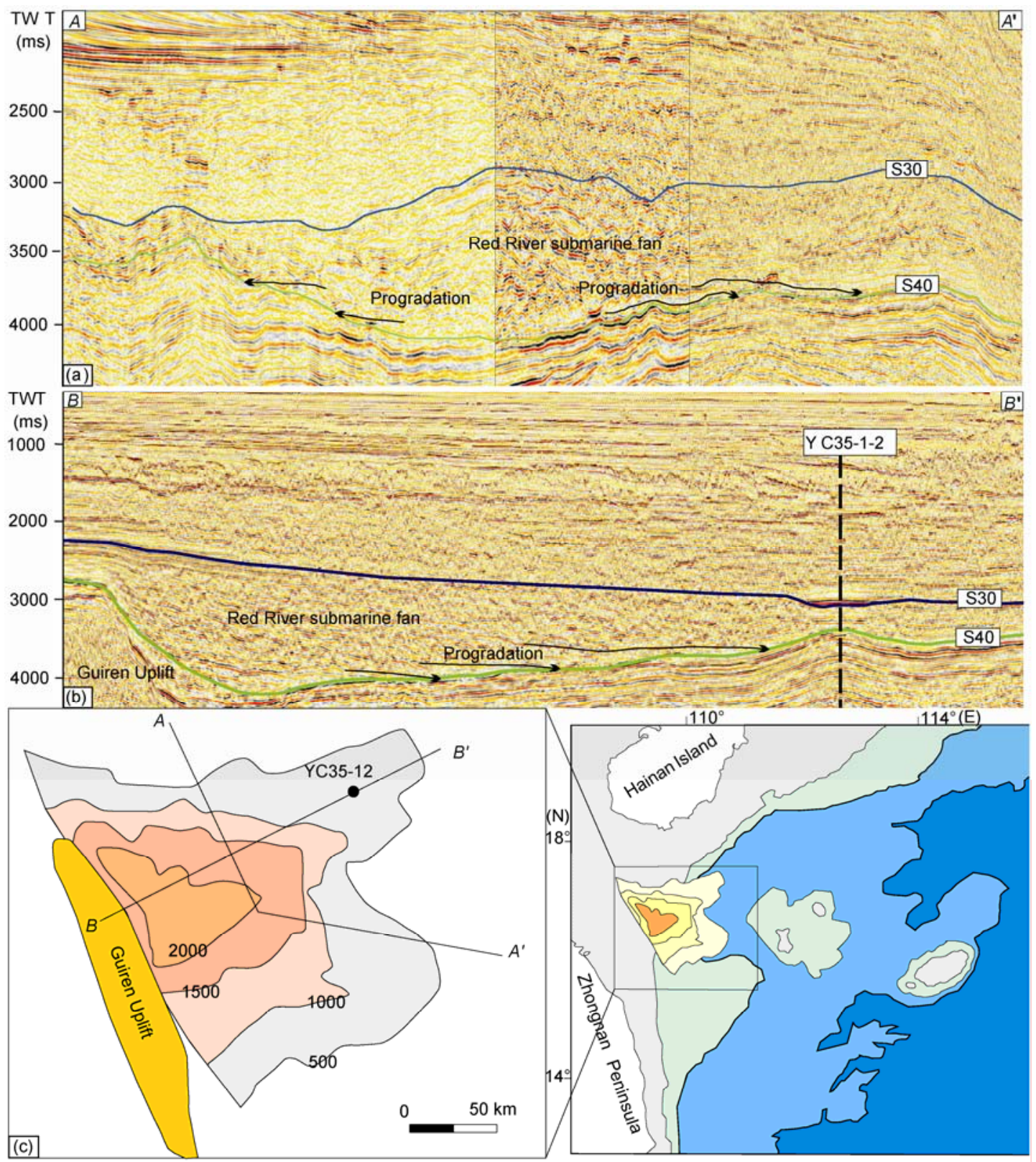

Figure 1 Typical seismic profiles showing the configuration and geometry of the Red River submarine fan and its plane distribution. $A-A^{\prime}$ is strike oriented and $B-B^{\prime}$ is in dip direction. (a) Bidirectional downlapping geometry; (b) wedge-shaped, oblique, progradational reflection configuration and thins out; (c) the thickness and distribution of Red River submarine fan.

Hemipelagic mudstones are primarily black and massive, with high gamma, density, and sonic, and low resistivity. Log curves are straight and close to the shale line. Lower-fan distal lobe deposits are formed under tubiditic and liquefied flows and consist of convoluted, ripple-cross laminated, and graded very fine-grained sandstones showing high gamma, density, sonic, and low resistivity.

The other two cycles covered by the cored interval show similar sedimentological characteristics as the bottom cycle described above; the difference is that there are no carbonate clasts near the bottom of these two cycles. Large clastic clasts decrease progressively upward from the oldest to the youngest cycle and the three cycles all together indicate an upward decrease in the proximal source and increase in the distal source. By integrating lithofacies from cores and log data in these three cycles, log models are established and are used to interpret facies and depositional environments in other cycles in the Huangliu Formation. Analysis shows that the Huangliu Formation is characterized by frequent interbedding of submarine fan gravity flow sandstones and hemipelagic mudstones. The older Huang2 Member consists of 6 submarine fan-hemipelagic cycles. The submarine fan portion is mainly outer fan channel and proximal lobe deposits that show ratty bell and/or box shapes on gamma logs. Gross sand is up to $64 \%$. The two cycles in the younger Huang1 Member, in constrast, have 23\% gross 

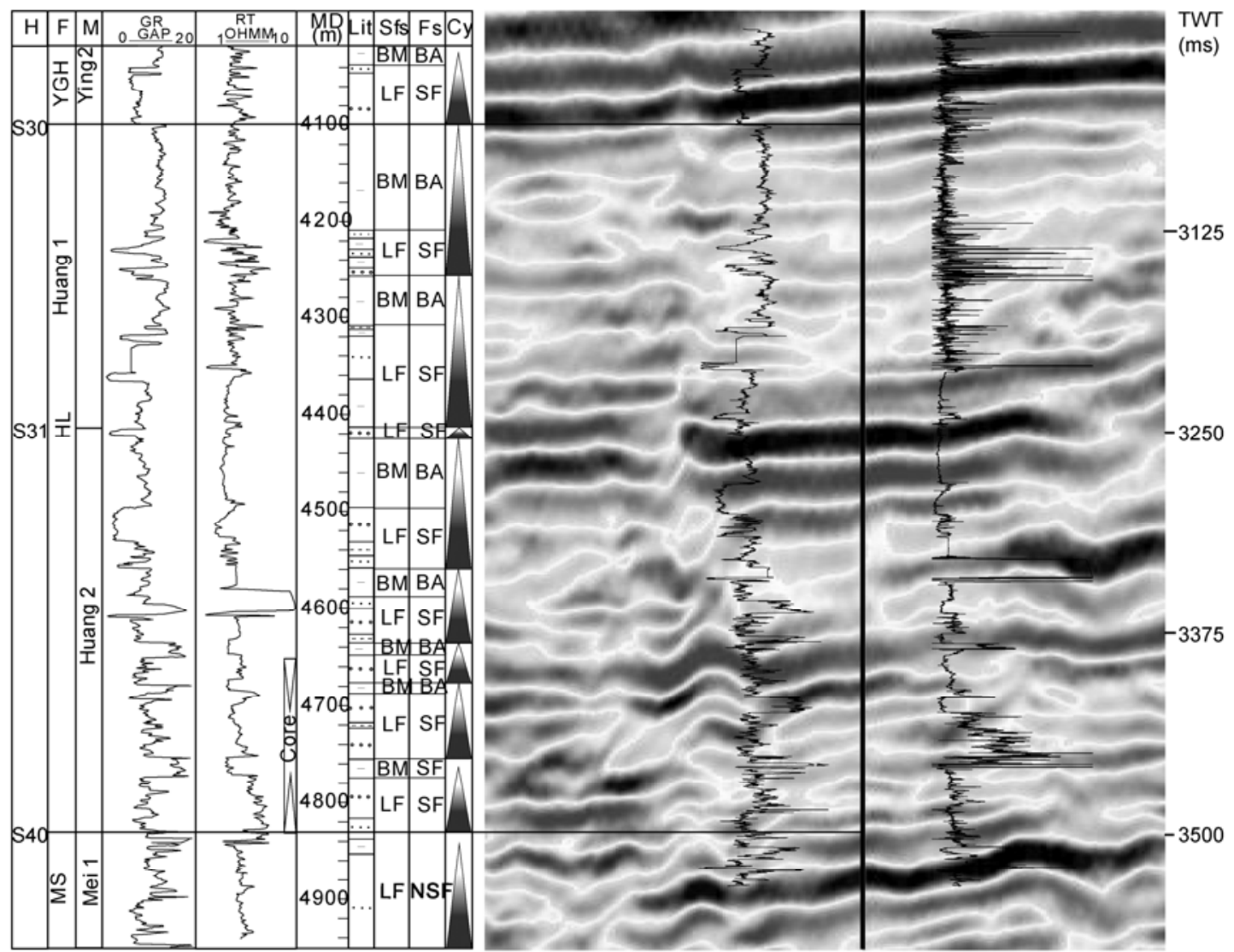

Figure 2 Log responses (YC35-1-2) and seismic-well log tie in the Huangliu Formation. H, Horizon; F, formation; M, member; MD, measured depth; Lit, lithology; Sfs, sub-facies; Fs, facies; Cy, cycle; BM, Bathyal mud; LF, lower fan; SF, submarine fan; NSF, nearshore Fan. YGH, Yinggerhai; HL, Huangliu; MS, Meishan.

sand and are dominated by hemipelagic mudstones mixed with thin bedded outer fan distal lobe deposits. The gamma logs are overall smooth, straight, and close to the mud base line. The content of clasts in the Huangliu Formation decreases upward. This and the vertical facies distribution in the formation are in accordance with the seismic facies and the overall rise in relative sea level during the Huangliu Stage.

Based on facies and their association analysis from seismic, well log, and core data, the depositional unit is interpreted as a large sand-/mud- rich submarine fan.

\section{Provenance analyses}

From the distribution of the Red River submarine fan, it seems that there are three potential provenances: the Guiren Uplift, the Hainan Uplift, and Red River system (Figure 1).

During the Huangliu Stage, the Guiren Uplift is dominated by carbonate platform deposits [3]. If it is the principal source, the fan should consist primarily of carbonate clasts, or at least show a mixing of carbonates and clastics. Core data from YC35-1-2 show that the fan consists predominately of clastic deposits, with only a small amount of car- bonate clasts. Guiren Uplift is, thus, unlikely the major source. Meanwhile, rivers (for instance the Meigong River), located onshore Vietnam and west of the Guiren Uplift, are mainly oriented north-south and medium- to large-sized rivers do not flow eastward to the junction between the Yinggehai and the Qiongdongnan basins.

From seismic data, the Huangliu Formation typically shows onlap onto the Hainan Uplift (Figure 4(d)) and there is no progradational reflection configuration from the uplift to the deeper basin. The YC26-1-1 well located to the north of the fan consists mainly of thick grey-black shale in the Huangliu Formation. All these observations suggest that the Hainan Uplift is also unlikely the main source for the Red River submarine fan.

To evaluate the possibility of the Red River as the major source, regional seismic profiles in the Yinggehai and Qiongdongnan basins are analysized in detail. On profiles from the northwest of the Yinggehai Basin to the west of the Qiongdongnan Basin (Figure 4(a)), large-scale oblique, progradational reflection configurations, with local erosional scours, are identified between S40 and S30 in the northwest of the Yinggehai Basin (Figure 4(b)). This is the Red River Delta, which has an area of over $10000 \mathrm{~km}^{2}$. Further southeastward, a slope break is developed in front 


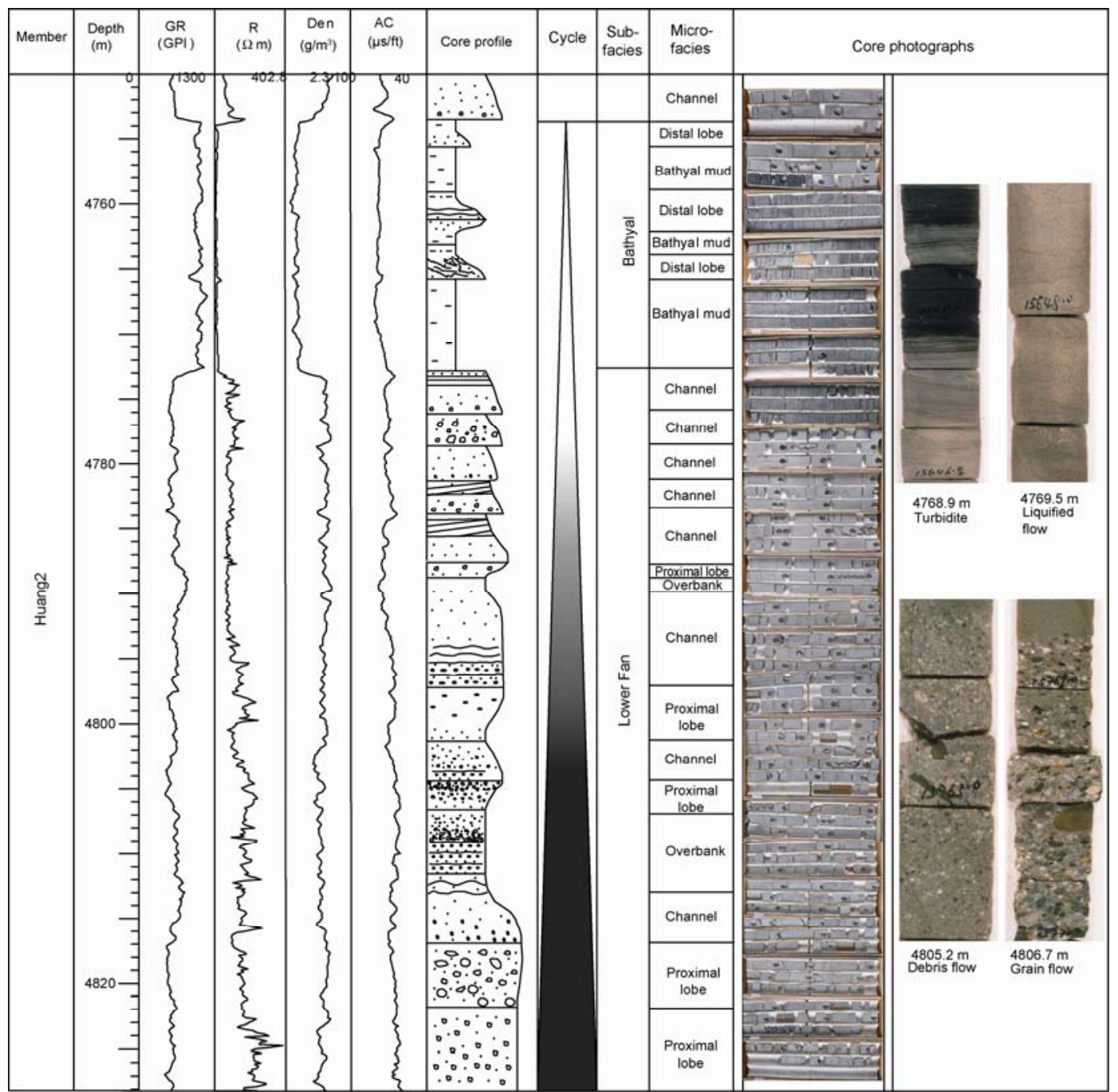

Figure 3 Rock-log characteristics of YC35-1-2.

of the delta. Above the break there are incised channels and below it strata thickness increases significantly. In the Huangliu Formation itself, a channel-levee complex with a complicated reflection configuration is developed (Figure $4(c)$ ). The complex is characterized by channel erosional scours near the bottom. Deposits confined in these scours show weak-middle amplitude, middle reflection continuity on seismic. Levee deposits show convex-up, high amplitude, middle-high continuous reflection. The reflections of these deposits together show a "gull-wing" geometry, typical to many submarine fans with well-developed channel-levees. However, the fan is only about $500 \mathrm{~km}^{2}$, and such as small feature is interpreted as an inter-slope mini-basin fan. To the south of the small fan, there is common occurrence of the channel erosional scours (Figure 4(a), (d)). Further south, located at the junction between the Yinggehai and the Qiongdongnan basins, is the main body of the Red River submarine fan (Figures 1(a), 4(e)). In summary, the Red River depositional system during Huangliu Stage is a large system and is composed of the Red
River Delta in the north of the Yinggehai Basin, the upper fan with canyons and/or incised channels and small fans in the inter-slope mini-basins southeastward, and the Red River submarine fan further southeastward at the junction between the Yinggehai and the Qiongdongnan basins. Both the Red River Delta and its submarine fan, the Red River submarine fan, cover an area over $10000 \mathrm{~km}^{2}$.

The integrated study shows that during late Middle Miocene a distinct shelf break was developed at and/or near the boundary between the Yinggehai and the Qiongdongnan basins under the affect of the Dongsha movement. Meanwhile, the tectonic event also leads to a large-scale relative sea-level fall in the Yinggehai Basin. The Red River system, in response, shifted dramatically basinward towards the boundary between these two basins, resulting in the quick growth of the sandy submarine fan.

Heavy mineral analysis is also conducted to further investigate the source of the submarine fan (Figure 5). Heavy mineral assemblage from the Red River source is characterized by high magnetite and garnet, low zircon and tourmaline, 


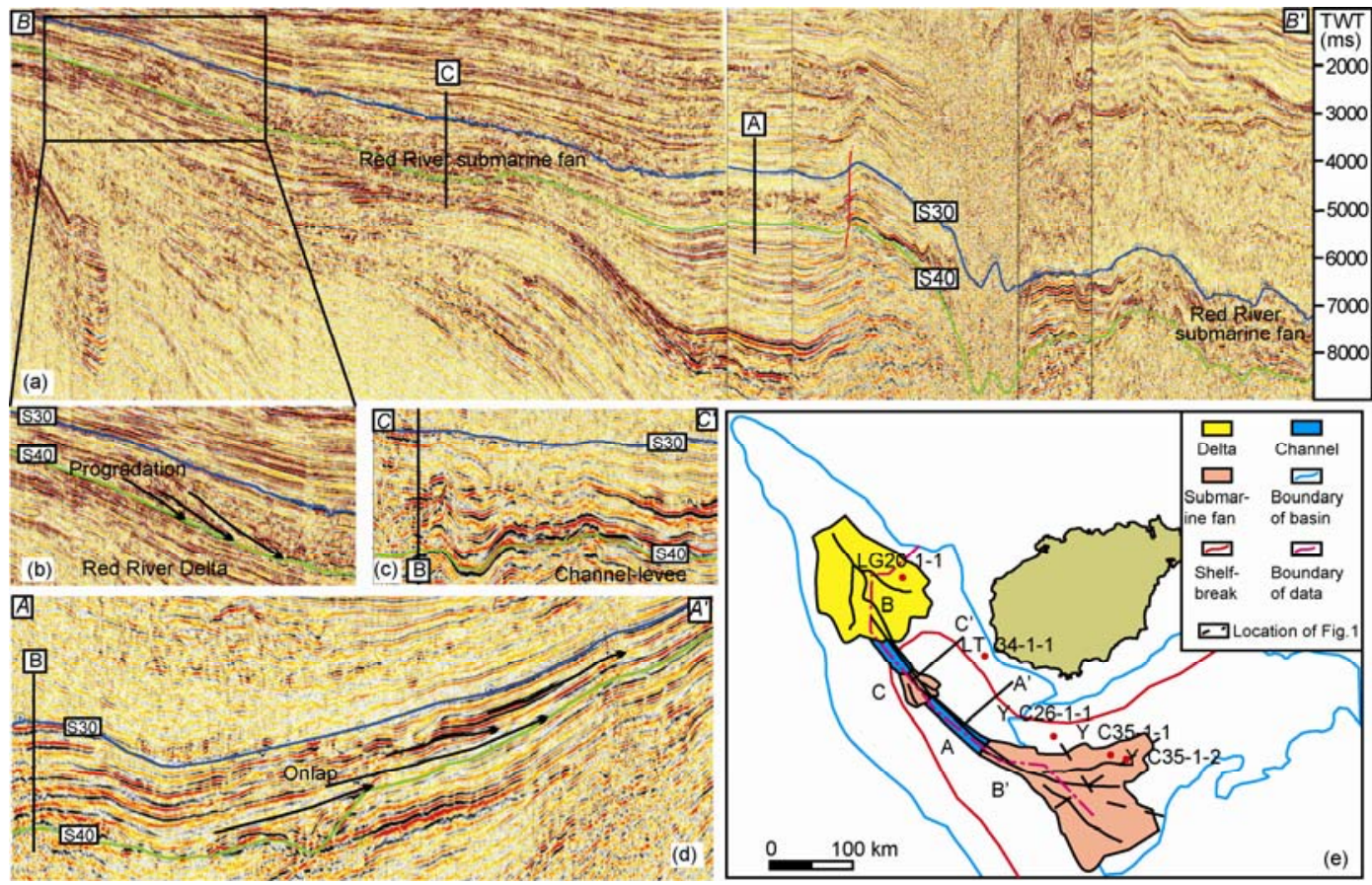

Figure 4 Characteristics of the Red River submarine fan. (a) Seismic profile along depositional dip of the Red River system; (b) large-scale oblique, progradational reflection configurations of the Red River Delta; (c) channel-levee complex; (d) channel erosional scours and onlapping of the fan deposits onto the Hainan Island; (e) distribution of the Red River system. (a), (b), (c), and (e) show that the Red River Delta, the channel-levee complex, and the Red River submarine fan all together lead to a delta-channel/submarine canyon-submarine fan depositional system; (d) indicates that Hainan Island is not the major source of the submarine fan. $A-A^{\prime}, B-B^{\prime}$, and $C-C^{\prime}$ in (e) showing the locations of the seismic profiles. A and $\mathrm{C}$ in (a) mark the positions where $A-A^{\prime}$ and $C-C^{\prime}$ cross with $B-B^{\prime}$; B in (c) and (d) marks the positions where profile $B-B^{\prime}$ crosses with profiles $A-A^{\prime}$ and $C-C^{\prime}$ respectively.

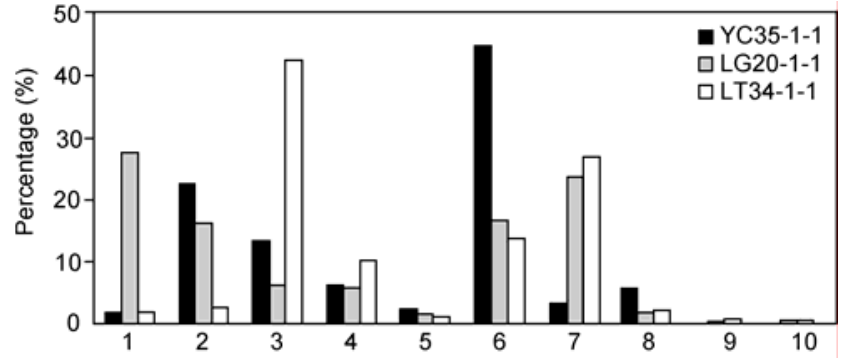

Figure 5 Provenance analysis based on heavy mineral assemblages. Well LG20-1-1 is representative of the Red River provenance and well LT341-1 of Hainan Island provenance. The heavy mineral assemblage from well YC35-1-1 is more similar to that in the well LG20-1-1. 1, Magnetite; 2, gamet; 2 , zricon; 3 , toumaline; 5 , rufile; 6 , white titanium; 7 , hematite limonite; 8 , anatase; 9 , zoistie; 10 , amphibole.

low ZTR, and a small proportion of white titanium, suggesting a metamorphic provenance. This assemblage is represented by the LG20-1-1 well, in which there are $26 \%$ ZTR, $16 \%$ garnet, $21 \%$ magnetite, and $16.5 \%$ white titanium. Deposits sourced from the Hainan Island typically consist of high zircon, tourmaline and white titanium, relatively high ZTR, and low garnet, indicating an intrusive provenance. This assemblage is represented by the LT341-1 well, in which there are 55\% ZTR, $1.9 \%$ garnet, $1.3 \%$ magnetite, and $14.7 \%$ white titanium.

Data from the Huangliu Fromation in YC35-1-1 show a heavy mineral assemblage with 22\% ZRT, 23\% garnet, $1.6 \%$ magnetite, and $44 \%$ white titanium. With overall low ZRT and high garnet content, this heavy mineral assemblage is very similar to that from the Red River source, indicating that the Red River rather than the Hainan Island is the major source for the submarine fan. The assemblage also suggests that neither the Guiren uplift nor the Yuedong area are the major source since both of them are dominated by carbonate deposition when the fan is laid.

\section{Geological background of the Red River submarine fan}

Based on the analysis above, the Huangliu Stage (10.5-5.5 $\mathrm{Ma}$ ) is the main period when the Red River submarine fan is developed. Since Pliocene, the growth of the fan stopped and in replace it is a central canyon with a length of hundreds of kilometers. It is most probably that to the southeast tip of the canyon, at the end of the Xisha Trough, large submarine fans are developed. Due to the lack of seismic data in this region, however, their occurrence still needs to be verified. Overall, sediments transported to the submarine fan by the Red River have significantly decreased since Pliocene. This is in accordance with the uplift of the Tibetan Plateau and the evolution of the Red River system [4-9]. 
Between about 13-9 Ma, the Tibetan Plateau underwent intense uplift and erosion. Material eroded from the plateau provided sufficient sediments for the growth of the Red River submarine fan. A significant marine regression occurred at 10.5 Ma under the affect of Dongsha Movement and at that time the shelf-break was close to the No.1 Fault Zone. This overall background controlled the initial deposition of the Red River submarine fan in Ledong Depression. Since 5.5 Ma, however, the Red River submarine fan suddenly disappeared because of very limited sediment supply. Replacing it is the development of the Central Canyon and the distal fan in the Xisha Through. This clear change in sedimentology needs to be further investigated. Clark et al. [10] suggested that the early Yangtze River system, including the Jinsha River and the Dadu River, joined the Red River and all flowed into the Yinggehai Basin. This drainage pattern, however, was altered by the turning of the Ailao-Red River No. 1 Fault into a dextral slip fault and the resultant uplift of the Western Yunnan Plateau. The Jinsha River and the Dadu River changed their flowing direction to the east and joined the Yangtze River [4,10,11], resulting in a dramatic decrease in sediments transported through the Red River. This hypothesis, however, needs to be further tested and the study of the evolution of the Red River submarine fan is, thus, significant to reveal the history of the Red River.

\section{Conclusions}

A huge sand-/mud-rich submarine fan is developed at the junction between the Yinggehai Basin and the Qiongdongnan Basin during Late Miocene (Huangliu Stage, 10.5-5.5 $\mathrm{Ma}$ ). The fan covers an area of over $10000 \mathrm{~km}^{2}$, and has a maximum thickness of $2000 \mathrm{~m}$. The fan is sourced by mixed carbonates from the adjacent Guiren Uplift and clastics from the Red River during its early stage. However, the Guiren Uplift is not the major source and sediments are primarily from the paleo Red River. Red River submarine fan is the major elements of the Red River depositional system. The study also suggests that the growth of the fan is in accordance with the uplift of the Tibetan Plateau and the evolution of the Red River.

The discovery of the Red River submarine fan not only provides important evidence for the uplift of the Tibetan Plateau and the evolution of the Red River, but also points out a new direction for deepwater hydrocarbon exploration in the northern South China Sea.

The authors thank Zhu Weilin, chief scientist of the National Basic Research Program of China, for his support and guidance in the study. The authors also thank the management and technicians in the Zhanjiang Branch of the CNOOC Research Center for preparing the data and geological discussions. This work was supported by the National Basic Research Program of China (2009CB219407) and the National Natural Science Foundation of China (40572067).

1 Wang E Q. An important coupling mechanism of mountain and lateral foreland basins: Orogen and basin (in Chinese). Chinese Sci Bull, 2004, 4: 370-374

2 Reading H G, Richards M. Turbidite systems in deep-water basin margins classified by grain size and feeder system. AAPG Bull, 1994, 78: 792-822

3 Fraser A J, Matthews S J, Murphy R W. Petroleum Geology of Southeast Asia. London: The Geological Society, 1997. 1-436

4 Xiang H F, Wan J L, Han Z J, et al. Geological analysis and FT dating of the large-scale right-lateral strike-slip movement of the Red River fault zone. Sci China Ser D-Earth Sci, 2007, 50: 331-342

5 Lin C S, Liu J Y, Cai S X, et al. Depositional architecture and developing settings of large-scale incised valley and submarine gravity flow systems in the Yinggehai and Qiongdongnan basins, South China Sea. Chinese Sci Bull, 2001, 46: 690-693

6 Zhong D L, Ding L. A discussion of the process and mechanism of Tibetan Plateau uplifting (in Chinese). Sci China Ser D-Earth Sci, 1996, 4: 289-295

7 Clift P D, Lee J I, Blusztajn J, et al. Erosional response of South China to arc rifting and monsoonal strengthening recorded in the South China Sea. Mar Geol, 2002, 184: 207-226

8 Tapponnier P, Peltzer G, Armijo R, et al. On the mechanism of collision between India and Asia. In: Coward M P, Ries A C, eds. Collision Tectonics. Geol Soc Lond Spec Publ, 1986, 19: 115-157

9 Wang C S, Dai J G, Liu Z F, et al. The uplift history of the Tibetan Plateau and Himalaya and its approaches and techniques: A review (in Chinese). Earth Sci Front, 2009, 3: 1-30

10 Clark M K, Schoenbohm L M, Royden L H, et al. Surface uplift, tectonics, and erosion of Eastern Tibet from large-scale drainage patterns. Tectonics, 2004, 23: TC1006, doi: 10. 1029/2002TC001402

11 Morley C K. A tectonic model for the Tertiary evolution of strike-slip fault and rift basins in SE Asia. Tectonophysics, 2002, 347: 189-215

Open Access This article is distributed under the terms of the Creative Commons Attribution License which permits any use, distribution, and reproduction in any medium, provided the original author(s) and source are credited. 